\title{
A Statistical Portrait of Inuit with a Focus on Increasing Urbanization: Implications for Policy and Further Research
}

\author{
Marika Morris \\ Adjunct Research Professor, School of Canadian Studies, Carleton University
}

aboriginal policy studies Vol. 5, no. 2, 2016, pp. 4-31

This article can be found at:

http://ejournals.library.ualberta.ca/index.php/aps/article/view/27045

ISSN: 1923-3299

Article DOI: http://dx.doi.org/10.5663/aps.v5i2.27045

aboriginal policy studies is an online, peer-reviewed and multidisciplinary journal that publishes original, scholarly, and policy-relevant research on issues relevant to Métis, non-status Indians and urban Aboriginal people in Canada. For more information, please contact us at apsjournal@ualberta.ca or visit our website at www.nativestudies.ualberta.ca/research/aboriginal-policy-studies-aps.

UNIVERSITY OF ALBERTA

FACULTY OF NATIVE STUDIES 


\title{
A Statistical Portrait of Inuit with a Focus on Increasing Urbanization: Implications for Policy and Further Research
}

\author{
Marika Morris \\ Adjunct Research Professor, School of Canadian Studies, Carleton University
}

\begin{abstract}
Over a quarter of Inuit in Canada now live outside Inuit Nunangat (Inuit traditional lands). Many have migrated to large Canadian urban centres such as Edmonton, Winnipeg, Ottawa, and Montreal. This article pieces together data from the Census, National Household Survey, Aboriginal People's Survey, and General Social Survey on Victimization to create a statistical profile of today's Inuit in terms of income, employment, education, health, housing, crime and safety, and culture and language, and the context in which these data should be read. The article discusses the implications of the increasing urbanization of Inuit for policy and research, and concludes that support for innovative Inuit services in urban areas is necessary.
\end{abstract}

\section{Introduction}

Twenty-seven percent of Inuit now live outside Inuit Nunangat ("where Inuit live"), Inuit traditional lands including Nunavut, Nunavik (northern Quebec), Nunatsiavut (Labrador), and the Inuvialuit region of the Northwest Territories (Statistics Canada 2015). Over a third of these live in Census Metropolitan Areas (CMAs), particularly Edmonton, Montreal, Winnipeg, St. John's, and Ottawa. The trend toward urbanization among Inuit is growing because of problematic living conditions in the north-namely, overcrowded housing, food insecurity, lack of economic and educational opportunities, and limited access to medical care. Gaps exist between Inuit wellbeing and that of the general population of Canada, yet Canadian cities are not fully prepared to facilitate the transition from northern hamlets to large southern urban areas. This article uses various Statistics Canada sources, such as the most recent Census/National Household Survey data (2011b), the 2012 Aboriginal Peoples Survey (APS), and the 2009 General Social Survey on Victimization, for which information is available for Nunangat. This creates a statistical profile of Inuit in Canada with particular attention to the growing urbanization of Inuit. The data are placed in the context of qualitative research with urban Inuit, and teasing out implications of the increasing urbanization of Inuit for policy and practice.

It is important to look at Inuit separately when reporting data for all Indigenous peoples because Inuit are historically, culturally, and linguistically distinct from First Nations and Métis; Inuit are one of three Indigenous groups recognized in the Canadian Constitution, the other two being First Nations ("Indians") and Métis; and Inuit tend to fare worse than other Indigenous groups on many statistical indicators of income, employment, health, and life expectancy. To lump them in with other groups hides the disparity between Inuit and other Indigenous groups, and Inuit and other Canadians. 
Statistics can sometimes paint a portrait of major socioeconomic and health problems among Inuit without taking into account their diversity, strengths, and resilience, how challenges came about, or what Inuit themselves are doing about the problems that face them. This article seeks to provide some of the context that is missing from most statistical portraits.

In the interests of full disclosure, the author is a member of Statistics Canada's Advisory Committee on Social Conditions, and also has had a working relationship with some Inuit organizations named in this article, such as Pauktuutit Inuit Women of Canada and Mamisarvik Healing Centre.

\section{Growing Urban Populations of Inuit}

Non-Inuit Indigenous peoples have been migrating to cities for a long time and have set up services in urban areas. Some First Nations have even established urban reserves. Inuit who migrate to cities, however, are often thousands of kilometres from their traditional homelands. The urbanization of Inuit is a newer phenomenon, with implications for a wide range of issues, including the potential spread of HIV/AIDS as a result of increasing mobility to and from isolated Inuit communities and the demand for housing and services in urban areas. It also poses a challenge for urban Inuit-how to be Inuit when Inuit cultural identity is so tied to the land.

Tungasuvvingat Inuit (TI), an Inuit-specific social service agency established in Ottawa in 1987, reports on the growing, though more recent, trend: "Ontario's Inuit population has grown from under 100 in 1987 to over 2,500 today, the majority of which having accessed TI services. Urban migration of Inuit from the north to southern locations continues on an upward trend" (TI 2014, 6). Statistics Canada data for the urban Inuit population do not match those of urban Inuit social service agencies, probably because the social service agencies also deal with transient and homeless populations, which Statistics Canada cannot reliably count. Nevertheless, all sources agree that urban Inuit constitute a growing population.

As of 2011, slightly less than three-quarters of Inuit (73.1 percent), or 43,460 people, lived in Inuit Nunangat (Statistics Canada 2013). For the first time, over a quarter of the Inuit population now lives outside Inuit traditional lands, which make up about a third of Canada's land mass. Of these, over a third (37.5 percent) live in major metropolitan centres. It is important to note that because of the difference in how data are collected in the north versus in cities, the undercounting of Inuit in urban areas is inevitable within the parameters of current budgets and methods of outreach.

In remote areas, the Census/National Household Survey (NHS) is collected in person by a Statistics Canada enumerator. In urban areas, people receive the paper survey in the mail or a letter with a link and access code for the online version (Statistics Canada 2011b). In-person enumeration can help ensure that people with low literacy skills can participate; however, urban Inuit (like other urban dwellers) simply get the paper survey or online option letter at their door. This is not the best way to capture everyone in a group that has 
a significant number of persons without a high school education, nor those who have no doors at which they can receive a survey, nor those who may be focussed on survival rather than filling out government forms that provide no obvious or immediate benefit. Statistics Canada does make more of a follow-up effort to help people participating in the mandatory Census. In 2016, the voluntary NHS will be dropped in favour of restoring the mandatory long-form Census.

The Census/NHS is conducted in most of Canada in May, but in the north the 2011 enumeration may have occurred between February and April to reach people before they went out on the land (Statistics Canada 2011a). This is an excellent way of catching people at home in the north, but not a good way of catching urban Inuit. Many Inuit start leaving for the north in May to stay with relatives or friends for the summer, so they may not be captured in either location.

With these important limitations in mind, we turn to what Statistics Canada data can tell us. The data outlined in Table 1 are tracking a shift over time in urban Inuit population growth.

TABLE 1: Inuit population in selected Canadian Census Metropolitan Areas (CMAs)

\begin{tabular}{|l|l|l|l|}
\hline $\begin{array}{l}\text { Census Metropolitan } \\
\text { Area }\end{array}$ & $\begin{array}{l}\text { Inuit population in } \\
\mathbf{1 9 9 1} \text { (Kishigami } \\
\mathbf{2 0 0 2 ,} \text { citing Statistics } \\
\text { Canada) }\end{array}$ & $\begin{array}{l}\text { Inuit population in } \\
\mathbf{2 0 1 1} \text { (Statistics } \\
\text { Canada 2013) }\end{array}$ & $\begin{array}{l}\text { Percentage } \\
\text { increase }\end{array}$ \\
\hline Edmonton & 840 & 1,115 & $33 \%$ \\
\hline Montreal & 775 & 900 & $16 \%$ \\
\hline St. John's & 345 & 680 & $97 \%$ \\
\hline
\end{tabular}

To put these numbers in perspective, it is useful to know that the Inuit population of Edmonton exceeds that of most northern Inuit communities. For example, Nain is the most highly populated Inuit community in Nunatsiavut, with a population of 1,070 in 2011 (Inuit Tapiriit Kanatami 2015b). The Inuit population of Toronto (640) exceeds the population of the Nunavut communities of Grise Fiord (115) and Resolute Bay (170) put together (Inuit Tapiriit Kanatami 2015b).

Although the numbers of urban Inuit are small as a proportion of the population of cities, the rapidity of population growth is remarkable. For example, Winnipeg and Edmonton have large Indigenous populations, while Inuit are a minority. As indicated above, the Inuit population of Edmonton increased by thirty-three percent between 1991 and 2011. Statistics Canada (2009) noted that the increase in the Inuit population of Edmonton outpaced the growth in the First Nations population of that city.

In 2011, the cities with the largest numbers of Inuit were Edmonton, Montreal, OttawaGatineau, Yellowknife, and St. John's (Statistics Canada 2015). Statistics Canada reported a drop in the Inuit population of certain CMAs, such as Toronto, even though the numbers of urban Inuit are growing in Canada overall. We do not know whether this is a statistical 
artefact of comparing data from the 2006 mandatory Census with the 2011 voluntary NHS, or an actual shift has occurred. We also know two-thirds of the twenty-seven percent of Inuit now living outside Nunangat are not located in major cities, but we do not know which smaller communities they may be in or why. As of 2011, there were 1,570 Inuit living in British Columbia, of whom 385 lived in Vancouver and 95 in Victoria (ITK 2015b). This means there were 1,090 Inuit living in BC outside these major areas. Statistics Canada does not report on small numbers of people in specific locations for reasons of confidentiality, so in the event that there were, say, ten Inuit in Prince George, that data could not be released.

Inuit have a high fertility rate, and the Inuit population of Canada grew by eighteen percent between 2006 and 2011 (Statistics Canada 2015), so the growing numbers of urban Inuit are not necessarily associated with a depopulation of Inuit communities. Statistics Canada estimated the Inuit fertility rate at 2.7 children per woman in 2005-06, compared with 2.4 for First Nations women, 1.8 for Métis women, and 1.6 for non-Indigenous women (Malenfant and Morency 2011). Inuit are the youngest demographic group in Canada: More than half (fifty-four percent) of Inuit in 2011 were younger than twenty-five, compared with thirty percent of the non-Aboriginal population (Statistics Canada 2013). Inuit had a median age of twenty-three compared with a median age for First Nations people of twenty-six, Métis of thirty-one, and forty-one for non-Aboriginal people.

\section{Reasons for Urban Migration}

Budak (2014) noted a shift in the reasons for Inuit coming to urban centres:

Previously, Inuit may have fallen into southern circumstances, either because they've followed family members, fled bad circumstances, or simply got stuck after coming down for medical treatment. But increasingly, people are drawn to urban centres for the promise of a better life, whether for jobs, cheaper housing or higher quality health care. And as post-secondary education becomes more of a priority in the maturing territory, there will be a greater pull south for young Inuit, raising logical worries about cultural dilution and loss of language, especially among a new generation of Inuit that are being born in the south.

For a variety of reasons, certain urban centres are receiving an influx of Inuit, particularly Edmonton, Winnipeg, Montreal, St. John's, and Ottawa. Ottawa is a three-hour flight from Nunavut's capital, Iqaluit. Many Nunavut residents go to Ottawa for medical care, addiction treatment, school, to escape abusive situations, or to find work. Montreal is the gateway to Nunavik, the Inuit lands of northern Quebec. Winnipeg is directly south of some major western Nunavut communities such as Kangiqliniq (Rankin Inlet) and Qamani'tuaq (Baker Lake). There are direct flights to Rankin Inlet from Winnipeg. Edmonton is a frequent southern destination from Yellowknife, capital of the Northwest Territories (NWT). The Inuvialuit Inuit land-claim region is within the NWT. St. John's is the provincial capital of Newfoundland and Labrador, within which lies the Nunatsiavut Inuit region. Regional and language differences exist among Inuit, so these urban centres may primarily reflect the Inuit who live directly to the north of them. 
Boarding homes for Inuit land claims beneficiaries who need medical care not available in their own communities may stay at Iglualuk Boarding Home in Churchill, Larga House in Edmonton, Tammattaavik Boarding Home in Iqaluit, Larga House Baffin in Ottawa, Kivalliq Inuit Centre in Winnipeg, or Larga Kitikmeot Boarding Home in Yellowknife. The only residential Inuit treatment program for addictions which is open to Inuit from anywhere is in Ottawa. There is one other, located in Nunavik, for residents of Nunavik only.

In subsequent sections, factors pushing Inuit away from northern communities (overcrowded housing, lack of economic and educational opportunities, and lack of sufficient health and social services) and those pulling them toward urban centres are explored, along with the challenges and possibilities arising from this migration.

\section{Families, Children and Relationships}

Families and kinship groups are the cornerstone of Inuit life. Traditionally, "[e]ach person within a kinship group was valued for his or her contribution to the group's well-being and success" (Qikiqtani 2014). Residential schools played a major role in undermining Inuit families (Qikiqtani 2014). In the 1950s and 60s, even though the Indian residential school system was already known to be a failure, a network of schools was set up across the north in which Inuit children were taught from a southern, Euro-Canadian curriculum and were taught to be ashamed of who they were. The Truth and Reconciliation Commission (2015, 67) documented that some Inuit children "were sent to schools thousands of kilometres from their homes, and went years without seeing their parents." The TRC documented the widespread physical and sexual abuse of students, as well as their shaming (TRC 2015). The TRC also noted that because the history of the schools in the north is so recent, with the last of them having closed in the 1990s, and because the majority of the population in Nunavut and the Northwest Territories is Indigenous, "the per capita impact of the schools in the North is higher than anywhere else in the country. ... both the intergenerational impacts and the legacy of the schools ... are particularly strongly felt in the North." (67) "The consequence of the school system was a deep cultural and generational divide between children and their parents. Children who had lost the ability to speak in Inuktitut could no longer communicate with parents and grandparents who knew little to no English" (Qikiqtani 2014).

The impact of residential schools on Inuit family life cannot be overstated, as children returned to families with trauma that would lead many to substance abuse, suicide, and a repetition of the violence many had experienced (TRC 2015). Thus began an intergenerational cycle of trauma. Despite ongoing Inuit suffering and disruption, Statistics Canada recorded that the majority (sixty-six percent) of Inuit feel they have strong or very strong family ties (Wallace 2014). These are much stronger inside the Inuit Nunangat (seventy percent) than outside (fifty-seven percent), reflecting the consequences and challenges of urbanization. "Two-thirds (sixty-six percent) of Inuit reported that in a time of need they would turn only to family members for support; twenty-two percent reported 
they would turn to both family and non-relatives. Fewer than ten percent of Inuit would turn only to non-relatives, and five percent reported that they had no one to whom they could turn" (Wallace 2014). Inuit-specific organizations in urban areas can help mitigate this disruption in family connections, which can also be associated with a disruption in cultural and language connections. Bird (2009) described why Clyde River Inuk Meeka Otway became involved in the Edmonton Inuit Cultural Association:

Meeka Otway of Edmonton will tell you that living in a southern Canadian city can be tremendously isolating for an Inuk ... "When you live in a small community, you have your sisters, your cousins, your aunts, your dad, all ready to help you out at any given moment .... When you move to the city, you're completely isolated. Your life changes overnight. People can even go into depression."

Inuit in relationships with non-Inuit are another source of migration to urban centres. Research with Montreal Inuit undertaken by Kishigami (2002) found that second- and third-generation urban Inuit may become completely assimilated into the mainstream culture, losing their Inuit identity. This is particularly true for young people with an Inuk parent and a non-Inuk parent. Inuit have created unique services in one urban centre, Ottawa, such as the Ottawa Inuit Children's Centre (OICC), which offers a child care program for Inuit children up to age six in which young people learn Inuktitut, play with pretend uluit, and learn cultural practices such as throat singing and drum dancing. The OICC also offers parenting groups and counselling services. It is the only Inuit-specific child-focused service in an urban area in Canada. Most Inuit migrating to cities do not have access to such services; they often have trouble finding any affordable child care, which has an impact on pursuing paid work and studies:

Many Inuit women have children at a young age. As a result they arrive as students in Winnipeg with their children. The unavailability of daycare services, moreover the complete lack of culturally appropriate childcare, makes continuation of their education more difficult. Thus the necessity for Inuit childcare is urgent in order to ensure that Inuit women are included in government initiatives aimed at providing education and training for Inuit. (Bloy 2008, 13)

Budak (2010) outlined some of the misunderstandings that can happen when Inuit from small northern communities come to the south. Cultural norms such as sleeping with a newborn, carrying a baby in the hood of an amauti (traditional dress), or letting small children roam free may pique the interest of child-protection services in cities. Lowi (2005) concurred: "Those who know Montreal's Inuit community say virtually every Inuit parent in the city has either had a child taken away by youth protection, has been threatened with placement in an institution, or knows an Inuit family that has suffered the same fate." On her first day of school in Edmonton, Inuk Lynda Brown and her mother were called to the principal's office to be told it was inappropriate to send children to school in "slippers." Lynda was wearing sealskin kamiks. She became so ashamed and marginalized as a solitary Inuk child in the school she began telling people she was Chinese to fit in (Payne 2015). 
The custom of informal or "customary" adoption, in which children live with aunts, grandparents, other relatives, or friends, may also seem strange to non-Inuit.

\section{Culture and Languages}

Data show that Inuit languages (Inuktitut/Inuinnaqtun) are alive and well, and are among the most well-maintained of Indigenous languages in Canada. Yet the language skills of individual Inuit are being eroded, and this is likely to continue by generation and with the trend toward urbanization. Statistics Canada reported that the percentage of Inuit who could speak an Inuit language very well or relatively well fell from sixty-five percent in 2001 to fifty-five percent in 2012. The figure was seventy-five percent among Inuit living in Inuit Nunangat, compared with only ten percent among those outside Inuit Nunangat (Wallace 2014). Not surprisingly, ability also varied by age, as shown in Table 2.

TABLE 2: Inuit able to speak an Inuit language by age and region, 2012 Statistics Canada data from Wallace (2014)

\begin{tabular}{|l|l|l|}
\hline Inuit region & $\begin{array}{l}\text { Inuit aged 55 and older able } \\
\text { to speak an Inuit language } \\
\text { very well or relatively well, } \\
\mathbf{2 0 1 2}\end{array}$ & $\begin{array}{l}\text { Inuit aged 15 to 24 able to } \\
\text { speak an Inuit language } \\
\text { very well or relatively well, } \\
\mathbf{2 0 1 2}\end{array}$ \\
\hline Nunavut & $95 \%$ & $64 \%$ \\
\hline Nunavik (northern Quebec) & $96 \%$ & $95 \%$ \\
\hline Nunatsiavut (Labrador) & $51 \%$ & $9 \%$ \\
\hline $\begin{array}{l}\text { Inuvialuit region of Northwest } \\
\text { Territories }\end{array}$ & $43 \%$ & $11 \%$ \\
\hline
\end{tabular}

The Nunavik experience clearly shows that the language can be maintained and passed down to subsequent generations. For example, the Kativik School Board in Nunavik ensures that "students are taught in Inuktitut until the third grade, at which time they choose English or French as their language of instruction. The Inuit language and culture continue to be taught throughout primary and secondary school" (Makivik 2015). Although Nunavut has legislation that mandates a bilingual (English/Inuktitut) education, it is having difficulty meeting this requirement because there are insufficient numbers of fully qualified teachers able to speak Inuktitut (Auditor General of Canada 2013). As such, only one of the schools audited in the 2011-12 school year actually met the bilingual requirement for kindergarten to Grade 3 (Auditor General of Canada 2013).

In Nunavik and, to a certain extent, Nunavut, Inuktitut is being maintained despite it not having been taught in residential schools, and even some schools' active attempts to stamp it out, leaving negative associations with this experience: 
Children who spoke Inuktitut were punished. I remember their first punishment: They had to put their hands on the desk and got twenty slaps on the back of their hand. The second time they got thirty slaps on their bare bum in front of all the class. They were forced to eat a bar of soap. They would throw up for two or three days. They were told that it was because they spoke an evil language. (Qikiqtani 2014, 35)

Urban Inuktitut language maintenance will depend on the availability and use of language and cultural programs in the city. Patrick et al. (2013) described an Inuit language and literacy program in Ottawa that is intergenerational, open to whole families, and also includes cultural knowledge transmission. The Ottawa Inuit Children's Centre has child care facilities that teach Inuktitut and Inuit culture. Patrick et al. $(2013,49)$ noted that it is operating in a larger policy environment in which "funding and program directives for Indigenous language maintenance and promotion are virtually absent."

Inuit do not speak a uniform language. Several dialects of Inuinnaqtun and particularly of Inuktitut exist, some using a syllabic writing system and some using roman orthography. Since 2012, Inuit Tapiriit Kanatami's Autausiq Inuktut Titirausiq Task Group, made up of language experts from each Inuit region, consulted widely and hosted a Summit on the Unification of the Inuit Language Writing System in 2015. A unified system of writing could make it easier to create and share materials in Inuktitut, thus promoting language retention.

The orthography is not the only issue. In Inuit regions, language programs can concentrate on the language of the region (Inuinnaqtun or the particular dialect of Inuktitut). Language programs in urban areas face the challenge of which dialect to promote. In some areas, this may not be an issue because the direct north-south migration might mean that the Inuit of Montreal are primarily originally from Nunavik, and would therefore be familiar with that dialect. But cites like Toronto or even Edmonton might attract a range of Inuit from different dialectal regions.

Cultural retention is not just a matter for Inuit, but for all Canadians, most of whom are unaware of Inuit culture beyond a few stereotypes. One of the conclusions of the Qikiqtani Truth Commission $(2014,54)$ was that [d] espite many political, economic, and social changes in the twentieth century, Inuit have retained their distinct culture. As described in the Strengthening Inuit Culture section, they are one of the founding peoples of Canada with a culture that should be celebrated, strengthened, and made better known to other Canadians."

\section{Employment and Income}

For thousands of years, Inuit worked daily to survive and thrive. They made tools, trained dogs, hunted, harvested sea resources, prepared hides, sewed clothes, took care of children, and were engaged in cultural production-creating songs, dances, visual designs, small sculptures, and stories. Statistics Canada data on employment would not have considered any of this employment, because no money changed hands. Employment data are based 
on being paid for work. In that context, the employment indicators for Inuit are poor, because such economically productive activities as hunting and fishing are not counted as "employment" in government data.

Europeans and the Government of Canada played an active role in destroying traditional Inuit economy and livelihood. English and Scottish whalers began harvesting in Arctic waters in the 1700s, eventually leading to the depletion of one of the Inuit's main sources of food. Whale oil also provided the only source of heat, light, and fire above the tree line (ITK, 2015a). Forced resettlement also influenced food harvesting, as the food could no longer be followed. In the 1950s and 60s, the RCMP systematically killed huge numbers of Inuit dogsled teams because of suspected or actual canine encephalitis, resulting in the elimination of a main source of transportation and livelihood for many people (Qikiqtani 2014). In recent years, climate change has also had an impact on wildlife and country food sources. Inuit have also been harmed by the 2009 European Union ban on seal imports (Qikiqtani 2014). Many Inuit cannot survive solely off the land today, partly because of the depletion of traditional foods and partly because of the omnipresence and attraction of the cash economy, southern food, and consumer goods. In addition, older survival skills are being lost as a generation gap has emerged between mainly Inuktitut-speaking elders and a mainly English-speaking younger generation who, like other young people in Canada, are immersed in modern technology and mass culture (Morris and Crooks 2015).

It is difficult to find recent figures for Inuit employment from published Statistics Canada sources. Although providing much useful information, The Education and Employment Experiences of First Nations People Living Off Reserve, Inuit, and Métis: Selected Findings from the 2012 Aboriginal Peoples Survey splits all the data into "high school completers" and "high school leavers," so one cannot find a unified figure for Inuit aged 15 to 64 in the paid labour force, unemployed, and not in the paid labour force. I use "paid labour force" because many of the people who are not in the labour force as Statistics Canada understands it are providing unpaid labour and support to their families and communities. The document states that, at the time of the 2012 Aboriginal Peoples Survey (APS) interview, fifty-six percent of Inuit leavers and twenty-nine percent of completers were not doing paid work. Seventeen percent of leavers were unemployed, compared with nine percent of completers. Over a third (thirty-nine percent) of leavers were not in the paid labour force, compared with twenty percent of completers (Bougie et al. 2013).

Table 3 outlines the published 2006 data for employment rates by Indigenous identity group for the "core working age" group of those twenty-five to fifty-four-unlike most employment data, which are given for the fifteen to sixty-four age group. The figures for the latter would probably make for a starker difference, because younger people and older workers of any background have greater difficulty finding work, but being young/close to retirement age and Indigenous is a double disadvantage. 
TABLE 3: Employment rate for Canadians aged 25-54, by Indigenous identity, 2006 data (Statistics Canada 2010a)

\begin{tabular}{|l|l|}
\hline Population group & Employment rate \\
\hline All Canadians & $81.6 \%$ \\
\hline First Nations on reserve & $51.8 \%$ \\
\hline First Nations off reserve & $66.3 \%$ \\
\hline Métis & $74.6 \%$ \\
\hline Inuit & $61.1 \%$ \\
\hline
\end{tabular}

Lack of economic opportunity in their home communities is driving Inuit migration to cities. This is despite the growing number of highly paid jobs being created in the north in resource-extraction industries. For example, Inuit Tapiriit Kanatami President Terry Audla (2012) testified before the House of Commons Finance Committee that although there are many economic opportunities in the north, Inuit are not fully benefitting from them.

Pauktuutit Inuit Women of Canada and its academic partners studied the effects of mining in the Nunavut community of Qamani'tuaq (Baker Lake) (Kudloo et al., 2014). Despite an Inuit Impact Benefit Agreement (IIBA) guaranteeing that Inuit would be employed by the mine, Inuit formed just one-quarter of the mine workforce, and were overrepresented as temporary workers. The mine also had a difficult time retaining Inuit. Some Inuit in the local community had little or no experience with regular employment, and were expected to leave home for two weeks, work for fourteen days, and then return home for two weeks. It was difficult to acclimatize or ease into paid work. As well, racism and other inappropriate behavior, particularly toward Inuit women, was a major problem. Alcoholism and violence increased. Lack of child care prevented many women from taking advantage of mine employment, and those who did were separated from children for two weeks at a time, which caused family disruption. There were insufficient services in the community to deal with the increase in social problems that accompanied the mine opening. The mine is slated for closure in 2017.

Although the two-weeks-off period could be used for traditional activities on the land, the wage economy does not fit well with the traditional economy because wildlife do not follow resource-extraction company schedules. The best type of employment opportunities for Inuit in the north might be jobs in which Inuit can balance paid with traditional economic activities, in which Inuktitut can be spoken, that do not require lengthy time away from family, and that are flexible enough to accommodate those who need to adjust gradually to waged work or who have responsibilities to provide their families and communities with country foods or other services. 
The 2012 APS asked a question about engaging in traditional activities. The data show that seventy-four percent of Inuit adults (eighty-one percent of men and sixty-eight percent of women) had taken part in at least one traditional activity in the past year, such as making clothing or footwear, arts and crafts, hunting, fishing, trapping, or gathering wild plants. Of Inuit living in Nunangat, eighty-two percent had engaged in these activities in the previous year, compared with fifty-five percent of those outside Nunangat (Wallace 2014). One-fifth of Inuit adults in Nunangat used these activities to supplement their income (Bougie et al. 2013), compared with fourteen percent of all Inuit (Wallace 2014). More commonly, Inuit engaged in hunting, fishing, trapping, or gathering for personal or family use (ninety-five percent), for pleasure (eighty-two percent), and to share with others in the community (sixty-four percent) (Wallace 2014).

\section{Education}

In 2012, data from the Aboriginal Peoples Survey (APS) show that forty-two percent of Inuit aged eighteen to forty-four had a high school diploma or the equivalent, compared with seventy-two percent of First Nations and seventy-seven percent of Métis (Statistics Canada 2013). Data from the 2011 National Household Survey show that eighty-nine percent of the Canadian population had a high school diploma or the equivalent. Of Inuit high school graduates, fifteen percent had left school and returned later to finish their diploma (Bougie et al 2013). "Men commonly dropped out due to a desire to work, money problems, school problems, and lack of interest. "Pregnancy/childcare responsibilities" was reported by one-quarter of off-reserve First Nations and Métis women and thirty-eight percent of Inuit women who did not complete high school” (Bougie et al. 2013).

Interestingly, there is an unexpected difference between Inuit and other Canadians as well as the members of other Indigenous groups in terms of the characteristics of those most likely to complete high school. For both the general Canadian population and other Indigenous groups, frequent changes of school unrelated to natural grade progression (i.e., the change from elementary to middle or high school) is correlated with lower likelihood of completing high school. For Inuit, the opposite is true. One quarter (twenty-five percent) of Inuit who completed high school changed elementary school three or more times, compared with twelve percent of Inuit who did not complete high school. Inuit who completed high school were more likely to have had to change schools because their family had moved (Bougie et al 2013). The statistics do not tell us the story behind the idea that mobility of Inuit contributes to educational success. It is possible that Inuit families move to larger communities in which schools may be better-resourced, or that they are moving to find work and improve the family income.

It is not surprising that Inuit high school leavers are more likely than completers to have siblings who dropped out (eighty-one percent compared to fifty-four percent), and less likely to have a mother who completed high school (twenty-four percent versus fifty-two percent) or a father who completed high school (twenty percent compared with fifty-three percent) (Bougie et al. 2013). However, these data also say something about Inuit resilience. 
Even though about half of Inuit high school completers had siblings who dropped out and parents who did not complete high school, they nevertheless continued their education to get a high school diploma. About a quarter of high school leavers and completers reported that racism had been a problem at their school (Bougie et al. 2013).

Graduation from high school and the quality of that education are just the beginning. Once Inuit get to college or university, there are further challenges. Small colleges in the North-Aurora College in Yellowknife and Nunavut Arctic College in Iqaluit, and their branches-offer a limited range of programs. There is no university in the north. Inuit are attracted to cities for post-secondary education and training. Half of Inuit (fifty percent) with a postsecondary qualification had to move to get it (Bougie et al. 2013). Those Inuit who do not finish are more likely than First Nations or Métis counterparts to say that it was "too difficult to be away from home." Inadequate academic preparation, the need to relocate at great distance, lack of funds, family responsibilities, and loss of support systems serve as barriers to Inuit post-secondary education (Malatest et al., 2004). As Table 4 shows, there is a large gap between Inuit with post-secondary qualifications and other Indigenous groups, as well as non-Indigenous Canadians. Statistics Canada did not report the figure for Inuit aged forty-five to sixty-four, or any figure falling that age range, in its publication about the educational attainment of Indigenous peoples.

TABLE 4: Post-secondary qualifications, 2012 Statistics Canada data from Bougie et al.

(2013)

\begin{tabular}{|l|l|}
\hline & Percentage of population aged 18-44 with a postsecondary qualification \\
\hline Inuit & $26 \%$ \\
\hline Off-reserve First Nations & $43 \%$ \\
\hline Métis & $47 \%$ \\
\hline Non-Aboriginal Canadians & $64 \%$ \\
\hline
\end{tabular}

Distance education, which could theoretically make postsecondary education more accessible to Inuit, has been used at the high school level for many years (Rogers 2015a). APS data revealed that about twenty percent of Inuit aged eighteen to forty-four with postsecondary credentials used some form of distance education, but sixty-six percent of those with postsecondary credentials reported that they did not have access to distance education because it was not possible for their program or did not fit their personal situation (Bougie et al.2013). A full sixty-six percent of Inuit female high school leavers cited personal or family responsibilities as keeping them from further education or training (Bougie et al. 2013); although distance education can help in that it can bring needed flexibility, it cannot replace child care and home care that could facilitate education for girls and young women.

Inuit are coming to cities for postsecondary education, and those who arrive from tightly-knit communities in which they and their culture are valued face a very different 
experience in urban areas. A qualitative study of Winnipeg Inuit found that isolation and loneliness are major problems for Inuit postsecondary students in urban areas (Bloy 2008). Most are coming from homes in remote areas where they know everyone in the community. In cities, they are merging into a different culture in which they do not feel they fit in and cannot make friends easily. Winnipeg Inuit post-secondary students said that what would help them is an Inuit student residence, culturally appropriate affordable child care, Inuitspecific elements on campus (rather than pan-Aboriginal services or centres that draw primarily or only on First Nations cultural touchstones), and more awareness of student funding sources (Bloy 2008). They also mentioned difficulties in getting into university with a Nunavut high school diploma (Bloy 2008). The quality of education in much of the north is not equivalent to that of southern Canada, which also makes it more difficult for Inuit students who do get into university and survive the culture shock and lack of resources.

Among those Inuit aged eighteen to forty-four who started but never finished postsecondary studies, thirty-five percent stopped because they had insufficient funds to continue to pay for their tuition or expenses; sixteen percent because they were pregnant or caring for their children; eighteen percent because of other family responsibilities; twelve percent because they lost interest or lacked motivation; ten percent because their courses were too hard (insufficient education to prepare them for the courses); eight percent because they got a job or wanted to work; and for six percent it was too difficult to be away from home (Bougie et al. 2013).

The National Inuit Youth Council supports Inuit education by highlighting successful young Inuit in the electronic and hard-copy magazine Nipiit. Inuit leader Mary Simon (2011) has called the education of Inuit "the greatest social policy challenge of our time," given that the residential school experience of so many living Inuit "shook our belief in ourselves." She said, "[I]f we are to restore the trust of parents who have been deeply hurt by their own educational experiences, we must build an education system grounded in the Inuit culture, history and worldview, and with respect for the role of parents."

Nunavut Sivuniksavut, a college program in Ottawa for students from Nunavut, was established in 1985 as a part of the Nunavut land-claims process. It offers courses on land claims, Inuit history, contemporary issues, the Inuktitut language, and job and study skills. The students visit organizations and prepare cultural performances for the wider community, as ambassadors for Inuit. They also travel internationally to meet Indigenous leaders and peoples in other parts of the world. The vast majority of graduates from the program (ninety-five percent) are either employed or pursuing further post-secondary studies (Rogers 2015c). The program is considered highly successful and being looked at as a model for other Inuit (Rogers 2015c).

The challenge for schools in urban areas in which there is a significant Inuit population is to incorporate learning about Inuit culture, which would also benefit non-Inuit students in terms of teaching them about an Indigenous culture of Canada that is spread across onethird of Canada's land mass, and learning the meaning and appropriate use of the symbols 
of Inuit culture that are often taken as representative of Canada, such as the inuksuk, or, rather, the inunguat which was used to represent the 2010 Vancouver Winter Olympics.

\section{Housing}

Inuit made their homes in the Arctic out of what was around them-snow in winter for the iglu and, in other seasons, sod, driftwood, or bone and hides for the qammaq. This enabled them to survive when European visitors to the Arctic perished.

Some Inuit remember when agents of the Canadian government told them to move into a settlement. The settlements were chosen on the basis of what was convenient for government agents to get to, and were not necessarily near good food sources (Qikiqtani 2014). Inuit were told there would be plenty of food and a good place to live, with running water, good schooling, and employment opportunities (Qikiqtani 2014). These promises were not honoured in full. In some cases, Inuit remembered trying to move back to their qamaq, but found that it had been destroyed (Qikiqtani 2014). Life in settlements governed by Qallunaat (non-Inuit, i.e. Europeans) brought alcohol and drugs to Inuit for the first time (Qikiqtani 2014).

As Canadians whose homes establish Canada's sovereignty and natural resource rights in the Arctic, and who make up a significant portion of the Canadian Rangers who provide military and strategic surveillance in the Arctic, Inuit expect to share in the living standards of other Canadians. The 2011 National Household Survey found, however, that twenty-five percent of Inuit but only three percent of other Canadians lived in overcrowded households (Wallace 2014). The percentage of overcrowding for Inuit was down marginally from twenty-nine percent in 2001. As Table 5, shows, the problem of overcrowding is much greater for Inuit who live in the north.

TABLE 5: Percentage of Inuit living in overcrowded conditions, 2011 Statistics Canada data from Wallace (2014)

\begin{tabular}{|l|l|}
\hline & Percentage of Inuit living in overcrowded conditions \\
\hline All Inuit & $25 \%$ \\
\hline Inuit Nunangat & $33 \%$ \\
\hline Nunavut & $34 \%$ \\
\hline Nunavik & $43 \%$ \\
\hline Inuvialuit region & $15 \%$ \\
\hline \multicolumn{1}{|c|}{ Nunatsiavut } & $13 \%$ \\
\hline Inuit outside Nunangat & $5 \%$ \\
\hline
\end{tabular}


Inuit Tapiriit Kanatami (2007) noted that overcrowded conditions facilitate the spread of infectious diseases, particularly respiratory diseases, as well as fostering family violence and poor achievement in school.

Riva et al. (2014) found that among a sample of 822 Inuit adults in Nunavik, greater household crowding was significantly associated with chronic stress and greater odds of being at risk on seven physiological indicators. The association between overcrowded housing and poorer health was maintained independent of sex, age, personal income levels, diet, and involvement in traditional activities. The association was even stronger for women than men, and significantly predicted coronary heart disease among women. The allostatic load of multiple stressors, to which overcrowded housing is a significant contributor, causes wear and tear on biological systems. Statistics about Inuit health, housing, and violence should all be viewed together, as they are interrelated.

Lack of affordable housing in the North is an issue with wide-ranging effects. The International Polar Year Inuit Health Survey of over 1,900 Inuit households in thirty-six Northern communities found that one in five households was providing shelter to at least one person who was homeless (Minich et al. 2011). Some Inuit migrating to Montreal are doing so to escape abuse in the home (Saturviit, 2015; Lowi 2005), as some have nowhere to live except with their abusers (Saturviit 2015).

Not only do too many Inuit live in aging, substandard housing, but the proportion of Inuit who live in housing in need of major repair is up:

In $2011,29 \%$ of Inuit, compared with $7 \%$ of the total population of Canada ... lived in dwellings that needed major repairs to, for example, correct defective wiring or plumbing or structural problems with walls, floors and ceilings. The percentage of Inuit living in homes needing major repairs was higher in 2011 than in 2001 (22\%). (Wallace 2014)

At a conference presentation by Statistics Canada analysts on Inuit housing, including the finding that a surprising number of Inuit were "satisfied with housing," an Inuk colleague became upset, as she saw the presentation of this finding as a justification for not doing anything about Inuit housing. The analysts were taken aback, as they did not see the data as political. In fact, however, the way data are framed can make the difference between taking action and excusing inaction.

Housing conditions are a factor pushing Inuit out of the north, but moving to southern Canada poses its own problems. Inuit who arrive in urban centres often do so with insufficient funds to obtain decent housing, and often lack employment; in fact, they may be moving to the urban centre to seek employment. However, if they do not have family or friends already in the urban centre who can take them in, they may have no choice but to seek emergency shelter. Temporary housing in urban centres is often not appropriate for Inuit, and can lead to negative outcomes (Bloy 2008). Although "temporary shelters" imply lack of permanence, many of the people who use such shelters are long-term homeless, mentally ill, or addicted persons. Kishigami (2008) found that homeless Inuit in Montreal sometimes avoided shelters because of racism on the part of staff and other clients. 
Housing repeatedly emerged as an important area of concern for Inuit arriving in Winnipeg, both in terms of receiving guidance about where to look for appropriate shelter and the availability of safe affordable temporary shelter while they attempt to find more permanent housing. Another repeated area of concern was the appropriateness of available housing to the needs of children. Inuit are a very young populace; a large percentage of women have their children before the age of 20 and many are single parents. Therefore, Inuit women migrating to the city often need child-appropriate housing, which is situated near green space, child care facilities and schools. (Bloy 2008, 8)

A number of urban centres have temporary residences for Inuit who are in town for medical treatment. In terms of permanent housing, Ottawa has an Inuit Non-Profit Housing Corporation that offers sixty-three units of rent-geared-to-income housing. Inuit in urban centres continue to be mobile; Statistics Canada (2004) found that thirty-seven percent of Inuit in Canada's large cities moved in the year previous to the 2001 Census.

Inuit urban homelessness is not just an issue of individual adults, but whole families. Newly arrived Inuit, some with low literacy skills, are left to navigate unintelligible, bureaucratic systems and a city full of strangers, when they come from communities of a few hundred people in which they know everyone (Bloy 2008). Currently, urban centres are set up to fail Inuit from remote communities. Considerable support is needed, including a first point of contact that can help them navigate the rest. However, at the moment, only Ottawa has the necessary Inuit infrastructure, and even this is insufficient to meet the growing numbers of Inuit moving to the city. In 2013-14, Tungasuvvingat Inuit (TI), an Ottawa Inuit social service agency, helped twenty people living on the street or in shelters to obtain permanent housing (TI, 2014), but there are more people in need of housing than there are units of affordable housing.

\section{Health and Well-being}

The Statistics Canada publication, Inuit Health: Selected Findings from the 2012 Aboriginal Peoples Survey (Wallace 2014), reports that forty-five percent of Inuit aged fifteen and older reported excellent or very good health compared with sixty-three percent of the Canadian population. One-third of Inuit reported good health, and eighteen percent, fair or poor health. Between 2001 and 2012, the percentage of Inuit who reported excellent or very good health fell from fifty-six percent to forty-five percent. The Inuit population is much younger than the Canadian average; poor health tends to increase with age, which makes these findings of concern.

Fifty-six percent of those outside Nunangat report excellent or very good health, compared to forty percent in Nunangat (Wallace 2014). Access to health care is very poor in Inuit regions, and many Inuit must leave their families and communities to seek care in distant cities. Wallace (2014) indicated that forty-three percent of Inuit reported having been diagnosed with at least one chronic condition. Half of these had one chronic condition; a quarter had two conditions; and the remaining quarter reported three or 
more chronic conditions. Interestingly, although Inuit outside Nunangat report feeling in better health, they were also much more likely (fifty-six percent) than Inuit in Nunangat (thirty-seven percent) to have been diagnosed with a chronic condition, possibly because of better access to medical professionals in larger urban centres. This is borne out by the APS data: Inuit in Inuit Nunangat were less likely to have contacted a health professional in the past year than were those living outside Inuit Nunangat: seventy percent versus eightyfour percent (Wallace 2014). Only thirty-nine percent of Inuit aged fifteen and older had a regular medical doctor (family doctor, pediatrician or general practitioner), compared with eighty-give percent of all Canadians aged fifteen and over. When asked why they did not have a regular doctor, sixty-five percent of Inuit respondents in Nunangat said that there were no doctors available in the area. The most common reason identified by Inuit who did not receive medical care when they needed it was that it was not available in the area (twenty-five percent) or that it was not available at the time required (fifteen percent).

Health behaviours also varied dramatically inside and outside Inuit Nunangat, with twenty-nine percent of Inuit living outside Nunangat smoking daily compared with sixty-three percent of Inuit inside (fifty-two percent for Inuit in total). Inside Nunangat, forty percent of Inuit had not consumed any alcohol within the previous twelve months, compared with seventeen percent of those outside Nunangat. Some Nunavut communities ban or restrict the sale of alcohol, and twelve-step programs favour abstention. Forty-six percent of Inuit in Nunavut had not consumed any alcohol within the previous twelve months. The totals for Inuit no matter where they lived varied by gender, with thirtysix percent of women and twenty-nine percent of men consuming no alcohol within the previous twelve months (Wallace 2014).

Despite the large proportion of Inuit who do not consume alcohol, heavy drinking was more of a problem among Inuit (twenty-six percent) than in the general Canadian population (eighteen percent). The Qikiqtani Truth Commission (2014) pointed out that "[g]iven the ongoing cultural dislocation and lack of employment opportunities, it should be no surprise that substance abuse continues to be a serious problem in Inuit communities" (75).

Drinking behaviour did not vary between Inuit in or outside Inuit Nunangat (twenty-six percent versus twenty-five percent). Again there was a gender difference, with more Inuit men (thirty percent) than Inuit women (twenty-three percent) reporting heavy drinking (Wallace 2014). There were distinct regional variations within Nunangat (Table 6), which may make a difference in urban areas because migration routes often follow north-south corridors.

Mental health is a serious issue in a population with large numbers of residential school survivors, a history of resettlement, and geographic, social, and economic isolation. The 2012 APS CANSIM table 577-0013 showed that one-fifth of Inuit (twenty-one percent) had seriously considered suicide, compared with twenty percent of First Nations and seventeen percent of Métis. In a comprehensive review of Inuit approaches to suicide prevention, Morris and Crooks (2015) found that Inuit have developed interesting models and services, all of which suffer from short-term, time-limited, and inadequate funding to meet the need. Many Inuit communities lack mental health services, and where mental health staff do exist, they are rarely Inuk (Qikiqtani 2014). 
TABLE 6: Percentage of Inuit drinking heavily by Inuit region, 2012 Statistics Canada data from Wallace (2014)

\begin{tabular}{|l|l|}
\hline & Percentage of Inuit drinking heavily \\
\hline Nunavut & $20 \%$ \\
\hline Nunavik & $34 \%$ \\
\hline Inuvialuit region & $38 \%$ \\
\hline Nunatsiavut & $47 \%$ \\
\hline
\end{tabular}

Thirty percent of Inuit aged eighteen and over were overweight and twenty-six percent were obese, using self-reported height and weight. There were no statistically significant differences between Inuit within and outside Nunangat on this measure (Wallace 2014). These data should be viewed within the context of food security, ${ }^{1}$ income, and food quality.

Statistics Canada reported that in 2012, forty-one percent of Inuit had experienced food insecurity in the previous year, compared with eight percent of all Canadians (Wallace 2014). More than half (fifty-three percent) of Inuit in Inuit Nunangat lived in households that experienced food insecurity, compared with seventeen percent of Inuit outside Inuit Nunangat. Food insecurity was worst in Nunavut (fifty-six percent), Nunavik (fifty-five percent), with rates of forty-five percent in Nunatsiavut and thirty-two percent in the Inuvialuit region. Food insecurity is linked to obesity (Wilde and Peterman 2006) and ill health (Cook et al. 2004). The food that is available in the north is very expensive and often not very nutritious, compounding issues of food security, obesity, and ill health. Flying food in from southern Canada has become a permanent condition, particularly as nothing can be grown in permafrost and current energy sources that might power greenhouses are unreliable and expensive. Industrial pollutants from other parts of the world have made their way into Inuit food sources: "Living beings, including Inuit and Arctic land and marine mammals, have some of the world's highest levels of exposure to mercury and other toxic chemicals, including DDT and PCBs. These contaminants accumulate in the fat of animals at the top of the food chain, which are then consumed by Inuit" (Qikiqtani 2014).

Historically, Inuit have had a traumatic relationship with the healthcare system. In the 1950s, medical ships came to screen Inuit for tuberculosis, and those with symptoms, including children, were taken to the south for treatment-often without their consent and without being able to say goodbye or keep in touch with their families (Grygier 1997). Some children never returned because records were lost, they died in hospital, and/or their families did not know where they were cared for or buried. Some families were never

1 Food insecurity refers to situations in which, for example, purchased or country food does not last and there is not enough money to buy more; a household cannot afford to eat balanced meals; or household members cut the size of their meals or skip meals because there is not enough money for food (Wallace 2014). 
informed about what happened to their loved ones (Qikiqtani 2014). "Being left alone while family members were sent away to hospital" and "Having been sent away to hospital for a long time" figure in a list of traumatic experiences from which Inuit need to heal, on which list also figure "being sent to prison" and "rape/child molestation" (Arnakaq 2010). All are forms of separation, isolation, or alienation from family.

Inuit who live in urban areas may have better access to health care than in the north, but still face challenges. Some urban Inuit have found it a frustrating process to get a health card or Non-Insured Health Benefits (N) card (Bloy 2008). Even when covered by insurance, Winnipeg Inuit, for example, had to pay up-front for health services (including dental care, eye care, and prescription drugs) and wait for reimbursement, which was a problem when they did not have the money to pay up-front (Bloy 2008, 6-7).

In 2012, the Government of Canada dismantled the National Aboriginal Health Organization (NAHO) and its Inuit health research centre, Inuit Tuttarvingat. Funding was also withdrawn from national Aboriginal organizations, including Inuit organizations, for health-related projects. Despite having lost most of its funding in 2012, Mamisarvik Healing Centre continues to serve Inuit with piecemeal funding from various sources that only allows it to accepts clients who are paid for by, for example, the government of Nunavut or Correctional Service Canada. Without adequate funding in proportion to the need, Inuit continue to try to help other Inuit heal and develop healthier habits in the face of many challenges (Morris and Crooks 2015). Inuit have developed their own healing imagery, such as the Iceberg Healing Model (Arnakaq 2010). Inuit have also established residences in a number of urban areas for those who need medical treatment. The statistics paint a portrait of a people rising to meet an overwhelming challenge without adequate support.

\section{Crime and Safety}

A study of police-reported crime in Inuit Nunangat found that the rate of violent incidents there was nine times as high as in the rest of Canada (Statistics Canada 2010b). The 200708 Inuit Health Survey in Nunavut (Galloway and Saudny 2012) found that thirty-one percent of respondents experienced severe physical abuse as children, and fifty-two percent of women and twenty-two percent of men reported having experienced severe sexual abuse during childhood. This is a legacy of residential schools, and the replication by some of what was done to them (TRC 2015). Inuit safety concerns should be viewed in conjunction with data on housing and healing services.

Saturviit Inuit Women's Association of Nunavik (2015) released a detailed report prepared in partnership with an academic researcher who interviewed 108 women from seven Nunavik communities and Montreal in 2013, ranging in age from eighteen to eightyfive years old. The women were interviewed about their lives and concerns, and named violence and lack of housing as the top challenges and barriers for women. Three-quarters of the women surveyed had experienced violence in the home, and almost half had experienced sexual assault. In its National Strategy to Prevent Abuse in Inuit Communities, Pauktuutit Inuit Women of Canada (2006) stated that "most Inuit have been victims of 
sexual, physical or emotional abuse or have witnessed a close family member being abuse, assaulted or killed. Abusers are often survivors of abuse themselves-abuse that occurred in the community, in the residential schools, or in their own families. Abuse creates a cycle of fear, shame, anger, addictions and violence that passes from one generation to the next ..." (1). Pauktuutit has called for more Inuit healing resources and training, multi-purpose healing facilities in communities, public awareness campaigns for Inuit, and alternatives to corrections such as community-based justice initiatives (Pauktuutit 2006).

There are no available statistics on violence against Inuit in urban communities, as statistics on violence are not kept by Inuit identity in these areas. Nevertheless, Inuit who are migrating from the north to escape violence need services in the south to overcome the wide-ranging effects of trauma (Saturviit 2015). Mainstream mental health services tend to view psychological distress as an individual problem, treating it with methods such as pharmacology and cognitive behavioural therapy, when the range and reasons for trauma and its effects on Inuit require culturally informed and culturally sensitive approaches, such as learning about the reasons for the widespread trauma among Inuit; reconnecting with the land, culture, language, spirit, and Inuit Quajimajatuqangit (Inuit cultural values/ traditional knowledge); learning healthy relationship skills; building on strengths and resilience; and feeling a sense of pride (Morris and Crooks 2015).

\section{Conclusion and Implications for Research and Policy}

Anyone who loses family bonds, livelihoods, and the right to make decisions about where and how to live is going to suffer physically and emotionally, and so are that person's family members. The statistics about Inuit health, employment, and education are not surprising. That the majority of Inuit are participating in a new future symbolized by Nunavut, and in the energy and activity of Inuit in cities establishing services for other Inuit, speaks to Inuit resilience and commitment to doing what is best for each other, demonstrating the Inuit Qaujimajatuqangit (traditional knowledge) principles of Pijitsirniq (serving others), Qanuqtuurunnarniq (being resourceful in solving problems), and Piliriqatigiingniq (working together for a common purpose).

There are many possible avenues of further research with urban Inuit. Because Statistics Canada will not release disaggregated data when there are few respondents for reasons of data quality and confidentiality, we cannot construct a statistical profile of Inuit in different cities. For example, we do not know whether the status of Inuit is relatively the same in Edmonton as in Winnipeg, or compare how Inuit are faring in Montreal relative to Ottawa. We know anecdotally that Inuit may be coming to these urban centres from different parts of the North, but no one has systematically tracked modern Inuit migration patterns or their implications. Most of the small qualitative studies of urban Inuit do not seem to document language or regional differences and more often than not treat Inuit as homogenous.

Gay, lesbian, bisexual, transgender, or queer (GLBTQ) First Nations people may be called "two-spirited." There is no such concept for Inuit. It is unknown whether some of the migration to urban centres is driven in part by young GLBTQ Inuit leaving small 
communities in which sexual minorities are not accepted. This would be a good area for future research, as northern and Christian fundamentalist taboos against same-sex relationships can also make it more difficult for Inuit who are members of sexual minorities to be open with family and friends, which can pose a mental health and suicide risk. Inuit such as Robbie Watt coming out publicly has helped to start a conversation, but other gay Inuit may remain fearful and marginalized.

Further research about Inuit migration patterns in Canada can help inform policies and practices regarding HIV/AIDS prevention and predicting needs for housing and services. It may also yield implications for health promotion messaging in urban areas, which tends to be individually focussed (i.e., smoking is bad for your health), whereas Inuit and members of other cultures may respond better to messaging that focuses on protecting and supporting the cultural group (i.e., quitting smoking helps other Inuit quit too).

The common thread in most of the research with Inuit in urban areas is the conclusion that much more support for Inuit-specific services is needed. In a study of urban Inuit homelessness, Kishigami (2008) suggested that an urban Inuit community centre where information and food could be shared is essential for the well-being of Inuit. Budak (2014) noted in her profile of urban Inuit that "[i]t is common to hear Inuit say they crave the company of other Inuit, or that maintaining strong cultural ties is a crucial part of how they managed the transition into city life." Kushwaha (2013) documented how Ottawa Inuit were able to maintain Inuit identity and connection to the land through the consuming of country foods, transfer of Inuit knowledge, cultural practices, and language made possible by local Inuit organizations. Bloy $(2008,14)$ concluded:

Without intervention, Inuit children growing up in Winnipeg will not be exposed to Inuktitut language, Inuit sewing, art, story telling, games, singing and drumming. Moreover they will not have the opportunity to experience the deep community connection between Inuit that has always been central to their survival as a people.

Recent research described in the Canadian Medical Association Journal shows that, for the first time, a decline was registered in the suicide rate of Inuit boys aged fifteen to nineteen in Iqaluit-the first decline in suicide in any Inuit population group. The rate of suicide for this Inuit age and gender group is twenty times the national average. Hicks hypothesizes that better-developed child care, education, and mental health services available in Iqaluit compared with smaller communities may play a role in the declining rate (Eggerston 2014). The solution is not necessarily for Inuit to move to large communities to get services, but for much-needed services to be available in small communities. Failure to ensure adequate health and social services, education, and economic opportunities for Inuit in northern hamlets is driving migration to cities (Bloy 2008).

We know that Inuit-specific services are important both in the north and in cities for the underlying trauma Inuit have experienced, along with all its manifestations-violence, addictions, homelessness, and marginalization-and that these services are either not present at all or are under-resourced (Alianait 2007). Inuit may experience racism in services and centres that are not designed for Inuit (Lowi 2005), and cultural alienation 
in services designed for "Aboriginal" people, which often are based only on First Nations cultural elements. In a study of urban Inuit in Winnipeg, "[t]he desire to situate an Inuit centre and residential facility separate from First Nations was universally expressed" (Bloy 2008, 6).

In November 2015, representatives of Inuit living in Ottawa, St. John's, Montreal, Toronto, Winnipeg, and Edmonton came together to develop an urban Inuit strategy, which they will release in 2016 (Bell 2015). This was the first time some Inuit from urban areas other than Ottawa had seen for themselves the services Ottawa Inuit had developed under the Tungasuvvingat Inuit (TI) umbrella, and this inspired them. Cities such as Edmonton, Winnipeg, and Montreal have urban Inuit organizations, but these are not the comprehensive and well-funded services offered through Tungasuvvingat Inuit (TI) in Ottawa, which is leading the development of the National Urban Inuit Strategy (Gregoire 2015). Despite a large Inuit population, Toronto has no services at all specifically for Inuit (Gregoire 2015). As a result of the urban strategy meeting, the first organization for Toronto Inuit was formed-Inuit of Toronto Urban Katimavik (Bell 2015). Funding for urban Inuit services remains a problem, because Inuit must compete for funds earmarked for urban "Aboriginal" services, which urban Inuit representatives do not believe is allocated fairly (Bell 2015). Many "Aboriginal" services in cities are grounded in First Nations cultural elements, such as the medicine wheel, sweat lodges, sweetgrass, smudging, eagle feathers, four directions, etc., which Inuit do not share (Morris and Crooks 2015).

Gregoire (2015) described the consultations that took place with urban Inuit across Canada about their major needs. These were:

- justice issues such as lack of translation services [into Inuktitut/Inuinnaqtun] and over-representation of Inuit in the justice system;

- child welfare and a lack of family services for Inuit families;

- lack of housing services and Inuit homelessness;

- healthcare service gaps such as primary healthcare in Inuktitut and preventative care;

- barriers to employment including work experience, training, language, childcare and criminal record pardons.

Inuit know how to support other Inuit, but funding is not always commensurate with the challenges. Barrera (2015) reported that Indigenous organizations in Canada experienced $\$ 60$ million in government cuts between 2012 and 2015, and that the greatest proportion was borne by Inuit organizations. According to the internal Assembly of First Nations analysis of Aboriginal Affairs and Northern Development Canada, Inuit organizations were cut by seventy-one percent, First Nations organizations by 65.5 percent, Métis organizations by thirty-nine percent, and non-status Indian organizations by fourteen percent.

Support for both Northern and urban Inuit services and organizations are important not only for Inuit, but for Canada as a whole. Canada has a special role to play in preserving and promoting Indigenous cultures and languages and incorporating knowledge of Indigenous cultures into mainstream curricula, as recommended by the Truth and Reconciliation Commission. Bloy asserts that "[a]s the trend to migrate to the south continues, urban centers across Canada must prepare to support the continuation of the Inuit culture and language or risk losing it forever" $(2008,13)$. 
Inuit organizations are not only lifelines for Inuit, but they are also sources of knowledge about Inuit culture for all Canadians. In order to make the best use of Inuit human resources and meet the needs of newcomers from the north, Canada must support Inuit efforts to establish Inuit-run services in urban areas, particularly housing, child care, health services, family services, employment, language, and cultural services. Wider outreach and inclusion of Inuit culture in mainstream Canadian schools and society would help avoid cultural misunderstandings, fear, and marginalization of Inuit in urban areas. An opportunity exists now for reconciliation and change. Inuit, like other distinct cultures, do not benefit from assimilation but from recognition of the value of their language and culture. Inuit have had to share the resources of the Arctic with other Canadians, and must also have an opportunity to share in the other resources that Canadians have. Reconciliation is a partnership, a respectful exchange of knowledge, and a sharing of resources. The gaps in well-being between Inuit and the rest of the Canadian population must be closed. 


\section{Bibliography}

Aboriginal Affairs and Northern Development Canada. 2011. "Urban Aboriginal Strategy Projects (2009-2010 Fiscal Year)." Accessed September 15, 2014. http://www. aadncaandc.gc.ca/eng/1316007831303\#chp9.

Alianait Inuit-Specific Mental Wellness Task Group. 2007. Alianait Inuit Mental Wellness Action Plan. Inuit Tapiriit Kanatami, Ottawa, Canada.

Arnakaq, M. 2010. The Iceberg Healing Manual. Pangnirtung, Nunavut.

Auditor General of Canada. 2013. 2013 November Report of the Auditor General of Canada. Ottawa: Office of the Auditor General of Canada. Accessed January 2, 2016. http:// www.oag-bvg.gc.ca/internet/English/nun_201311_e_38772.html\#hd5e.

Audla, Terry. 2012. "Mr. Terry Audla (President, Inuit Tapiriit Kanatami) at the Finance Committee," openparliament.ca, October 29th, 2012. Accessed January 17, 2015. openparliament.ca/committees/finance/41-1/84/terry-audla-1/only/.

Barrera, J. 2015. “Aboriginal Organizations Hit with $\$ 60$ Million Worth of Cuts, Inuit Faced Steepest Reduction: AFN Analysis." Aboriginal Peoples Television Network (APTN) National News, January 13. Accessed February 10, 2015. http://aptn.ca/ news/2015/01/13/aboriginal-organizations-hit-60-million-worth-cuts-inuitfaced-steepest-reduction-afn-analysis/.

Bell, J. 2015. "Southern Inuit to Unveil National Urban Strategy Next Year." Nunatsiaq News, November 10. Accessed January 10, 2016. http://www.nunatsiaqonline.ca/stories/ article/65674southern_inuit_to_unveil_national_urban_strategy_next_year/.

Bird, J. 2009. "National Organization Launched for Southern Inuit.” Nunatsiaq News, May 1. Accessed June 1, 2015. http://www.nunatsiaqonline.ca/archives/2009/905/90501/ news/nunavut/90501_2127.html.

Bloy, K. 2008. Winnipeg Urban Inuit Study, 2008. Winnipeg: Social Planning Council of Winnipeg.

Bougie, E., K. Kelly-Scott, and P. Arriagada.2013. The Education and Employment Experiences of First Nations People Living Off Reserve, Inuit, and Métis: Selected Findings from the 2012 Aboriginal Peoples Survey. Ottawa: Statistics Canada. Accessed January 15, 2015. http://www.statcan.gc.ca/pub/89-653-x/89-653-x2013001-eng.htm. 
Brown, L. 2011. "Urban Inuk Rising." Urban Inuk Uprising. Ottawa Inuit Children's Centre. Accessed January 5, 2015. http://www.ottawainuitchildrens.com/2012/05/post-2bea/.

Budak, J. 2010. “A Modern Migration: Inuit Go South.” Accessed July 7, 2014. http:// jasminebudak.com/2010/09/15/inuk-tropolis/.

Cook, J.T., D.A. Frank, C. Berkowitz, M.M. Black, P.H. Casey, D.B. Cutts, A.F. Meyers, N. Zaldivar, A. Skalicky, S. Levenson, T. Heeren and M. Nord. 2004. "Food Insecurity Is Associated with Adverse Health Outcomes among Human Infants and Toddlers." Journal of Nutrition 134(6): 1432-8.

Eggertson, L. 2014. "Suicide Rate Lower Among Boys in Iqaluit." Canadian Medical Association. Journal 186.18 (Dec 9, 2014). E665-6. doi:10.1503/cmaj.109-4935.

Galloway, T., and H. Saudny. 2012. Inuit Health Survey 2007-2008 Nunavut Community and Personal Wellness. Montreal: Centre for Indigenous Peoples' Nutrition and Environment, McGill University.

Gregoire, L. 2015. "Ottawa Org Building National Urban Inuit Strategy." Nunatsiaq News. October 13, 2015. Accessed January 1, 2015. http://www.nunatsiaqonline.ca/stories/ article/65674ottawa_org_building_national_urban_inuit_strategy/.

Grygier, P.S. 1997. A Long Way from Home: The Tuberculosis Epidemic among the Inuit. Montreal and Kingston, Canada: McGill-Queen's University Press.

Inuit Tapiriit Kanatami (ITK). 2015a. "Inuit and Europeans.” Accessed July 15, 2015. https:// www.itk.ca/about-inuit/inuit-and-europeans.

Inuit Tapiriit Kanatami (ITK). 2015b. "Inuit population.” Accessed January 10, 2016. https://www.itk.ca/about-inuit/inuit-population.

Inuit Tapiriit Kanatami (ITK). 2011. "Naasautit: Inuit Health Statistics." Ottawa: Inuit Quajisarvingat Knowledge Centre. Accessed July 14, 2015. http://www. inuitknowledge.ca/naasautit.

Kushwaha, A. 2013. The Significance of Nuna (the Land) and Urban Place-Making for Inuit Living in Ottawa, Ontario, Canada. Ph.D. diss., Carleton University, Ottawa.

Kishigami, N. 2008. “Homeless Inuit in Montréal.” Études/Inuit/Studies 32(1): 73-90. doi:10.7202/029820ar. 
Kishigami, N. 2002. "Inuit identities in Montreal, Canada." Études/Inuit/Studies 26 (1): 183-91. doi:10.7202/009279ar.

Kudloo, R., K. Czyzewski, F. Tester, N. Aaruaq, and S. Blangy. 2014. The Impact of Resource Extraction on Inuit Women and Families in Qamani'tuaq, Nunavut Territory. Ottawa and Vancouver: Pauktuutit Inuit Women of Canada and School of Social Work, University of British Columbia.

Lowi, E. 2005. “Urban Inuit Face a Life of Pain.” The Montreal Gazette, 29 October: A13.

Makivik Corporation. 2015. "Recent History and Demographics." Accessed June 3, 2015. http://www.makivik.org/recent-history-demographics/.

Malatest \& Associates Ltd. 2004. Aboriginal Peoples and Post-Secondary Education: What Educators Have Learned. Montreal: Canada Millennium Scholarship Foundation.

Malenfant, E.C., and J-D Morency. 2011. Population Projections by Aboriginal Identity in Canada, 2006 to 2031. Ottawa: Statistics Canada. Accessed June 3, 2015. http:// www.statcan.gc.ca/pub/91-552-x/91-552-x2011001-eng.htm.

Minich, K., H. Saudny, C. Lennie, M. Wood, Williamson-Bathory, Z. Cao, and G.M. Egeland. 2011. "Inuit Housing and Homelessness: Results from the International Polar Year Inuit Health Survey 2007-2008." International Journal of Circumpolar Health 70 (5): 520-31. doi:10.3402/ijch.v70i5.17858.

Morris, M., and C. Crooks. 2015. "Structural and Cultural Factors in Suicide Prevention: The Contrast between Mainstream and Inuit Approaches to Understanding and Preventing Suicide." Journal of Social Work Practice 2015 (July 3): 1-18. doi: 10.1080/02650533.2015.1050655.

Patrick, D., G. Budach and I. Muckpaloo. 2013. "Multiliteracies and Family Language Policy in an Urban Inuit Community." Language Policy 2013 (12): 47-62. doi:10.1007/ s10993-012-9258-3.

Pauktuutit Inuit Women of Canada. 2015. "Inuit Midwifery”" Accessed July 31, 2015. http:// pauktuutit.ca/health/maternal-health/midwifery/.

Pauktuutit Inuit Women of Canada. 2006. National Strategy to Prevent Abuse in Inuit Communities and Sharing Knowledge, Sharing Wisdom: A Guide to the National Strategy. Ottawa: Pauktuutit Inuit Women of Canada. 
Payne, E. 2015. “Ottawa's Urban Inuit Renaissance." Ottawa Citizen, April 17. Accessed June 1, 2015. http://ottawacitizen.com/news/local-news/ottawas-urban-inuitrenaissance.

Poore, A.G., F. Gagne, K.M. Barlow, J.E. Lydon, D.M. Taylor, and S.C. Wright. 2002. "Contact and the Personal/Group Discrimination Discrepancy in an Inuit Community." Journal of Psychology 136 (4) 371-83. doi:10.1080/00223980209604164.

Qikiqtani Inuit Association. 2014. Qikiqtani Truth Commission: Thematic Reports and Special Studies 1950-1975. QTC Final Report: Achieving Saimaqatiqiingniq. Iqaluit: Qikiqtani Inuit Association and Inhabit Media. Accessed June 3, 2015. http://www. qtcommission.ca/sites/default/files/public/thematic_reports/thematic_reports_ english_final_report.pdf.

Riva, M., P. Plusquellec, R-P Juster, E.A. Laouan-Sidi, B. Abdous, M. Lucas, S. Dery, and E. Dewailly. 2014. "Household Crowding is Associated with Higher Allostatic Load among the Inuit." Journal of Epidemiology and Community Health (Jan. 2). doi:10.1136/jech-2013-203270.

Rogers, S. 2015a. "Arviat High School Looks at Distance Ed to Graduate its Students." Nunatsiaq Online. June 26, 2015. Accessed June 28, 2015. http://www. nunatsiaqonline.ca/stories/article/65674arviat_high_school_looks_to_distance_ ed_to_graduate_its_students/.

Rogers, S. 2015b. "Inuit Language Task Force Moves toward Standardizing Written Inuktut." Nunatsiaq Online. February 4, 2015. Accessed February 5, 2015. http:// www.nunatsiaqonline.ca/stories/article/65674inuit_language_task_force_moves_ toward_standardizing_written_inuktut/.

Rogers, S. 2015c. "Majority of Nunavut Sivuniksavut Grads Find Jobs in Nunavut." Nunatsiaq Online. February 6, 2015. Accessed January 10, 2015. http://www.nunatsiaqonline. ca/stories/article/65674majority_of_nunavut_sivunisavut_grads_employed_in_ nunavut/.

Saturviit Inuit Women's Association of Nunavik. 2015. Bring Hope and Restore Peace: A Study Report on the Life and Concerns of Inuit Women in Nunavik. Inukjuak, Quebec: Saturviit Inuit Women's Association of Nunavik and the CommunityUniversity Research Alliance Leadership and Governance in Nunavut and Nunavik: Life Stories Analytical Perspectives, and Training.

Simon, M. 2011. First Canadians, Canadian First: National Strategy on Inuit Education. Ottawa: Inuit Tapiriit Kanatami. 
Statistics Canada. 2015. Aboriginal Population Statistics at a Glance. Catalogue no. 89-645X. Ottawa: Statistics Canada.

Statistics Canada. 2013. Aboriginal Peoples in Canada: First Nations People, Métis and Inuit. Catalogue no. 99-011-X2011001. Ottawa: Statistics Canada.

Statistics Canada. 2011a. Aboriginal Peoples Technical Report, National Household Survey. Ottawa: Statistics Canada. Accessed March 24, 2015. http://www12.statcan.gc.ca/ nhs-enm/2011/ref/reports-rapports/ap-pa/index-eng.cfm.

Statistics Canada. 2011b. National Household Survey User Guide. Ottawa: Statistics Canada.

Statistics Canada. 2010a. Aboriginal Statistics at a Glance. Ottawa: Statistics Canada.

Statistics Canada. 2010b. Police-Reported Crime in Inuit Nunangat. Ottawa, Minister of Industry.

Statistics Canada. 2009.2006 Aboriginal Population Profile for Edmonton. Ottawa: Minister of Industry. Accessed July 24, 2015. http://www.statcan.gc.ca/pub/89-638-x/2010003/ article/11077-eng.htm.

Statistics Canada. 2008. Aboriginal Peoples in Canada in 2006-Inuit, Métis and First Nations, 2006 Census. Ottawa, Minister of Industry.

Statistics Canada. 2004. Overview-The Inuit population in Canada: A profile of Canada's Inuit population. Ottawa: Minister of Industry.

Truth and Reconciliation Commission. 2015. Canada's Residential Schools: The Inuit and Northern Experience. The Final Report of the Truth and Reconciliation Commission of Canada, Volume 2. Montreal and Kingston: McGill-Queen's University Press.

Tungasuvvingat Inuit. 2014. Tungasuvvingat Inuit Annual Report 2013-2014. Ottawa: Tungasuvvingat Inuit.

Wallace, S. 2014. Inuit Health: Selected Findings from the 2012 Aboriginal Peoples Survey. Ottawa: Statistics Canada. Accessed March 3, 2015. http://www.statcan.gc.ca/ pub/89-653-x/89-653-x2014003-eng.htm.

Wilde, P., and J.N. Peterman. 2006. "Individual Weight Change Is Associated with Household Food Security Status." Journal of Nutrition 136(5): 1395-1400. 